\title{
JOURNAL
}

OF THE

\section{Franklin Institute}

OF THE STATE OF PENNSYLVANIA,

FOR THE PROMOTION OF THE MECHANIC ARTS.

Vol. CXXV.

MAY, I 888.

No. 5 .

The Franklin Institute is not responsible for the statements and opinions advanced by contributors to the JouRnal.

SOME RECENT ADVANCES IN PHOTOGRAPHY.

BY Fred. E. IVES.

The Lecturer was introduced by Prof. Edwin J. Housron, as follows:

It is unnecessary at the present stage of the world's progress to insist on the advantages of photography. We are fortunate in having with us this evening as a lecturer, on "Some Recent Advances in Photography," one who is himself a pioneer in this department of applied science. I allude to Mr. Frederic E. Ivis, a distinguished inventor in the field of photo-mechanical engraving, by which the production of type-printing plates directly from nature is made possible, and who was the first to devise and employ a practical process for obtaining accurate monochrome photographs of objects in all colors, or, as these pictures are styled, isochromatic photographs.

Whole No. Vor. CXXV.-(Third Series, Vol, xcv.) 
Mr. Wves then spoke as follows:

There is so much to be said on the subject of recent advances in photography, that it would take several lectures to cover the ground fairly well; I have therefore engaged only to speak of some. recent advances in photography, and shall devote most of my time to those branches with which I am most familiar.

The most important recent advances in photography are the rapid gelatine bromide dry plate process, the isoch romatic or colorsensitive processes, film photography, and the platinum and bromide paper printing processes-all of which have come into use within ten years past. The same period has also witnessed great advances in the applications of photography to the printing press, including the first commercially succcssful production of typeprinting plates direct from ordinary photographic negatives.

\section{THE DRK PLATE PROCESS.}

The modern rapid gelatine bromide dry plate differs from the old wet collodion plate in being from ten to roo times more sensitive, and in kecping for years before exposure or development. The increase of sensitiveness is valuable for many purposesespecially for making photographs of rapidly-moving bodies and objects that are dimly lighted; their keeping qualities render them useful for a great variety of purposes for which wet collodion plates are unsuitable. Because of these advantages, the introduction of this process has very greatly extended the application of photography, which is now largely employed by scientists in the pursuit of their investigations, by artists to assist them in their labors, by travellers to secure souvenirs of their journeys, and by thousands of people of both sexes, young and old, in the pursuit of pleasure.

The first successful gelatine bromide dry plates were made by Dr. Maddox, an amateur photographer, in England, in $187 \mathrm{x}$; and the first gelatine emulsion commercially produced was adverticed for sale by Mr. Burgess, in I 873 . These emulsions were not remarkably sensitive, although somewhat more so than wet collodion plates. It was not until 1878 that $\mathrm{Mr}$. Bennett, another amateur photographer, discovered that an emulsion of extraordinary sensitiveness could be produced by prolonged digestion at $32^{\circ} \mathrm{C}$. In that year many experimentalists produced plates that were prob- 
ably equal in every respect to the best commercial dry plates of to-day.

It took several years to convince practical photographers generally of the superiority of the gelatine dry plate method, but it has now superseded the collodion process for nearly all purposes, and thousands of important photographs have been made by it that would never have been made by the older method. The list includes photographic maps of the heavens, photographs of star and solar spectra a hundred times more perfect than could be produced on wet collodion plates, photographs of lightning flashes, balloon photographs, photographs of animals in motion and birds on the wing, etc.

One of the most popular applications of this process by amateurs is in the production of instantaneous pictures, by daylight with the so-called detective camera, and at night by the magnesium. flash light.

\section{FILM PHOTOGRAPHY.}

Film photography is a method of producing the rapid gelatine bromide process negatives on paper instead of glass. This method offers the important advantage that, as the support for the sensitive film is extremely light and flexible, it can be used from a roll, and a great many exposures made upon the contents of a single roll holder. After development, the film negatives can be stripped from the paper support, preserved between the leaves of books and printed from as well and as quickly as glass negatives. This method is most useful to travellers, but is not likely to be adopted to any extent for home work. Lantern slides have also been made on these films, and a hundred of them may be carried in a pocket without inconvenience.

THE GELATINE BROMDEF PRINTING PROCESS.

The gelatine bromide printing process is an application of the gelatine bromide process to the production of positive prints by development. Suitable paper is coated with the gelatine bromide cmulsion, and the development of the picture is effected with ferrous oxalate. The extreme sensitiveness of this paper makes it the easiest method we have for producing large prints from small negatives. The prints have a neutral tone that is pleasing and artistic. 
THE PLATINUM PRINTING PROCHSS.

The platinum printing process gives about the same effects as the bromide paper process, and is cheaper, but can be employed only for contact printing, or with the solar camera.

\section{ISOCHROMATIC PHOTOGRAPHY.}

Next in importance to the rapid gelatine dry plate process, is the isochromatic, or color-sensitive process. Ordinary photographic sensitive plates are comparatively insensitive to the green, and still more so to the yellow and red of the spectrum, so that those colors photograph much too dark, while blue and violet photograph too light. By means of plates made sensitive to the green, yellow and red rays, and employed in conjunction with light filters of colored glass, this defect may be corrected. Many paintings and art objects that could not be photographed successfully in the ordinary way because of their colors, are now reproduced in a most satisfactory manner by this method, which is variously known as the isochromatic, orthochromatic, and color-sensitive, or correctcolor-tone process. Bromide of silver is made sensitive to the green, yellow and red rays, by treatment with certain organic compounds, such as chlorophyl, cyanine, eosine, etc.

Dr. H. W. Vogel, of Berlin, was the first to discover that bromide of silver can be made sensitive to color in this manner. In the course of some experiments in spectrum photography, he observed that plates prepared by a certain process showed relatively more green sensitiveness than ordinary collodion bath plates, and at once set to work to discover the cause. It appeared that it might be due to the color of the film, which was reddish, and he tried the effect of dyeing the film, hoping that the light absorbed and held in the film by the dye would be forced to act upon the sensitive salt. It would be contrary to all known physical laws for the mere coloration of a sensitive film to produce this result, but Dr. Vogel found that certain dyes did, in some way, produce colorsensitiveness, and he went so far as to produce, in his laboratory, a photograph of a blue ribbon on a yellow background, in which the ribbon came out darker than the background. His effort to prove a false theory led to an important scientific discovery. His plates were not, however, sufficiently sensitive to coloi to have any com- 
mercial value, having, indeed, far less absolute color sensitiveness than the ordinary uncolored rapid gelatine dry plate of to-day; nor was the sensitiveness distributed throughout the lower portion of the spectrum, as it must be, in order to permit of the photographing of all colors correctly at one time.

Becquerel and Waterhouse, who soon after confirmed Dr. Vogel's results, cach discovered a new and better colorsensitizer. Becquerel, in 1875 , announced that by means of chlorophyl he had made plates from one-tenth to one-fifth as sensitive to the deep red of the prismatic spectrum as to the violet. Waterhouse, in 1876 , announced that he had obtained strong yellowgreen sensitiveness with eosine; he also made photographs of colored objects on the eosine plates, but as he employed no light filter, the blue and violet rays still did nearly all the work, and he reported the experiment a failure. Ducos du Hauron, of Paris, made some use of both chlorophyl and eosine in experiments in heliochromy in $1876-77$, but did not try to produce correct monochrome photographs of colors.

The first correct-color-tone photographs of objects in all colors were made by myself in the laboratory of Cornell University, in the summer of 1878 . They were made with collodion bromide emulsion plates, sensitized with myrtle-chlorophyl and an infusion of tea, and exposed through a light yellow medium. These plates were from twenty-five to fifty times more red-sensitive than those of Becquerel, and had also relatively sufficient sensitiveness to all other colors. I published the method in 1879 , but nobody tried it. Several years after, similar processes were announced in Europe, and, in i 886 , the FRAnkLin Institure, after a careful investigation, endorsed my claim to priority. Measured by results only, this original process leaves nothing to be desired, except the colors themselves, and is not equalled by any other yet discovered. It is the only process that will photograph the deep red pigments successfully, -but it is a comparatively troublesome and delicate process to operate, and is successful only in a bright light, and with chlorophyl obtained from certain kinds of leaves. It is also impossible to keep chlorophyl without considerable loss of sensitiveness, and it has never been employed successfully with gelatine dry plates. After several years of experiment, erythrosine and cyanine have been generally adopted, because they can be successfully 
etmployed with gelatine dry plates, which are far more convenient to use than collodion cmulsion, and also more sensitive.

In order to show the characteristic action of the most remarkable color-sensitizcrs, I have made photographs of the prismatic solar spectrum on plates prepared as follows:

(1) Pain collodion bromide emulsion. Shows, with short exposure, no action in or below the green.

(2) Collodion emulsion, with erythrosine. Shows, with same exposure, enomous action in the yellow, a great deal in the sreen, and none whatever in the red. This is the most powerful yellowsensitizer known.

(3) Collodion emulsion with cyanine. Shows, with same exposure, strong action in the orange-red and yellow, none in the green, and none in the deep red. This is the best red-sensitizer yet discovered for gelatine dry plates.

(4) Collodion emulsion, with year and a half old chlorophyl, which had been preserved by adding zinc powder to the alcoholic solution. Although the chlorophyl has lost two-thirds of its original sensitiveness to red and green, it is still superior to cyanine, both in extent and intensity of action, but has the disadvantage that it would have failed with a gelatine dry plate.*

Cyanine-erythrosine gelatine dry plates, although they do not compare at all favorably with chlorophyl collodion plates in refative color-sensitiveness, have greater absolute sensitiveness for all colors except deep red; and because of their greater general sensitiveness, easy preparation and keeping qualities, they have greater commercial value. The average photographer very much prefers sood
results by an easy process to better results by an easy process to better results by a more troublesome
one.

It is also a lamentable fact that the number of photographers who have any scientific knowledge of this subject is excecdingly small, and much that is being said and published about it is either
false or misleading.

In July, 1886 , the Chairman of a London photographic society, who pretended to have tried the orthochromatic processes, said he hat rever secn a photograph in which blue came out darker

Hince delivening this lecture, I have discovered a simple and certain acthod of producing strongly color-sensitise grelatine bromide plates by
means of chlorophy. This method will be published soon. 
than yellow. In December, of the same year, a well-known photographer said, at a meeting of the Photographic Society of Great Britain, that he believed orthochromatic photography to be a delusion; he added that he had not tried it, " nor did he intend to do so."*

Within three months past, a writer, having made some photographs on ordinary plates, exposed through a simple yellow colorscreen, announced that "the orthochromatic processes" do not succeed in making red or orange photograph lighter than blue, but make the color defect somewhat less conspicuous! The author of "A History of Photography, written as a practical guide and an introduction to its latest developments," published within six months past, ignores the subject altogether. Others go to the opposite extreme, and speak of color-sensitive gelatine dry plates that "can be used without the color-screen," which is of course true, because any plate can be so used, but is, nevertheless, a very misleading statement when made in this connection.

The scientific and practical value of these methods has been sufficiently proved, and it is clear to me that the better they are known, the more extensive will be their employment for many purposes.

\section{PHOTO-MECIANICAL ENGRAVING.}

The earliest experimenters in photography recognized the desirability of a photographic method of producing type blocks from nature, and the subject received a great deal of earnest attention for a long time before any successful method was realized. The chief problem that had to be solved was the automatic translation of the graduated tints or shades of the photograph into pure line or stipple. A great variety of methods were tried, and a few good examples produced from time to time; but no mechanically accurate or reliable method was ever suggested previous to 1878 . In August, of that year, Chas. Petit, of Paris, and myself, then at Cornell University, recognized, almost at the same moment, the principle upon which the first successful method was based. We did not, howcver, apply the principle in the same manner, and Petit's process was not commercially successful.

"On that occasion Mr. Thomas Bolas remarked, that "unless there was a gand conspiracy among eminent men in the scientific world to tell lics, there was something in orthochromatic photography." 
TIIT IVIS PROCESS.

The Ives process was introduced commercially in this city early in $188 \mathrm{I}$. It has been described a great many times in book and magazine pullications, and is now very well known. The invention is not, primarily, a plate-making process, but a process of producing, by purcly photo-mechanical means, a substitute for the hand-made pen or crayon drawings formerly required in the production of printing blocks by the aid of photography. The first operation is the production of a photographic relief, by a simple, well.known method, with bichromatized gelatine. $A$ film of bichromatized gelatine is first exposed to light under the ordinary photographic negative, then placed in water, where it swells up into relief, highest where the negative was most intense, and lowest where it was most transparent. A cast in plaster is then made from this wct gelatine relief; it has a perfectly white surface, but is high where a photographic print from the negative would be black, lower in the middle shades, and lowest in the whites. Aiter the production of this relief cast, the process is purely mechanical and perfectly simple and scientific. An inked pad or film of elastic $V$-shaped lines or dots is pressed against the surface of the relief cast, until the lines or dots are completely flattened out where they meet the hrighest parts of the cast; when it is removed, there remains impressed upon the cast an ink picture having the appearance of an ordinary photograph, but made up of sharply defined lines and dots, which graduate in size like those of a wood engraving, and can be photo-engraved exactly like a pen or crayon drawing, or transferred to zinc or copper and etched into relief. I have some of the relief casts here, one of them bearing the ink stipple impression. The operation of producing the impression is, as you see, extremely simple, and the result is wonderful. The elastic lines of the printing pad being $V$-shaped, secure mechanically accurate graduation from deep shadows to extreme high lights, and the general effect can be greatly modified at will by changing the pattern of lines and dots. The best results are secured by the employment of a special elastic compound, and special ink, the composition of which has not been published.

Petit, whose original specification dates the same week as my own, blackened the surface of a white photographic relicf, and cut in white lines, with a $V$-shaped tool, on a planing machine. Althongl 
the principle is substantially the same, the processes are perfectly distinct, and Petit's was a practical failure.

For more than a year, the Ives process was the only one in successful commercial operation in the world. Its first rival was a method introduced by Meisenbach, in Munich, in the latter part of the year i 882 .

TIE MEISENBACH PROCESS.

In this method, the photographic relief is not required, and the definite negative is made, at one operation, from a photographic positive on glass, like the well-known window transparencies. In order to accomplish this, a glass plate, bearing a tint consisting of fine lines cut through an opaque film, is placed between the positive and the sensitive plate, to cut the picture up into lines. So far, there is nothing new in the method, and if it were not more than this, it would be utterly unscientific and practically worthless. To illustrate this fact, I have made a photograph of such a positive through such a ruled tint on a large scale, which I will show on the screen. It will be seen that the result is a mere skeleton of the picture; half of the detail is lost, and that which remains appears in lines that do not graduate in size, like those of a wood engraving, but only in color, like a photograph. It would be impossible to make a good printing plate from such a negative. It is essential that this interposer, technically known as a "grating," shall not only divide the picture into lines, but also cause those lines to graduate in size as well as in color, and that it shall do all this without completely obscuring any detail of the positive picture. There are several ways in which this can be accomplished in a strictly accurate, scientific manner, and one of these is suggested, though not fairly described, in Meisenbach's patent specifcation. He makes only two distinct claims, neither of which was sufficiently novel or specific to be allowed in the U.S. Patent Office. The first is merely a device for securing, with this method, the pattern of black cross lines in the shadows and white cross lines in the lights, which was already a recognized characteristic of the Ives process plates; the second is his means for securing the necessary graduation in the size of the lines. It is of interest to note that this last claim, which alone suggests the true inwardness of Meisenbach's method, has been generally omitted from printed descriptions of the process-probably because its significance was 
not suspected. It consists of merely griving to the "grating" a very slight movement, at right angles to the direction of the lines during the exposurc. This operation can be so conducted that the result will be as if each line of the "grating" graduated in color from centre to edge. Without taking the trouble to demonstrate the fact, I will state that in a negative made under these conditions, the lines will be graduated in size as well as in color, being thinnest where they are narrowest, and stronger at the centre than at the edges. It is possible to produce a "grating" that will give this result directly, without the movement, by molding in pigmented gelatine upon plate glass from a type metal plate ruled in $V$-shaped lines; the printing film employed in the Ives process becomes a most perfect "grating" of this character if soaked in a suitable solution of dyestuff and then dried. Another method, which requires no movement, is to employ a "grating" having very narrow transparent lines, place it at some distance from the positive picture, and use a lens diaphragm having a diamond. shaped aperture. There are still other methods equally as good or better. It will be seen that in each of these cases we have really another application of the $V$-shape principle that had already been recognized and applied in a very different manner by Petit and myself. But even with the most perfect means for graduating the lines, this method will not succeed if we attempt to make the definite negatives by a dry-plate process, because the lines, which should graduate in size only, will naturally also graduate in color. They can be made to approximate to the required character only by employing the collodion and silver-bath process for making the negatives, and taking care to keep the silver bath in a peculiar condition, which favors the development of a coarse-grained, intense, superficial image that intensifies readily up to the extreme edge of each dot or line.

A microscopic examination of negatives produced by the two methods I have described shows a very striking difference in the appeatance of the lines; those in the Ives negative are perfectly sharp and smooth, while those in the Meisenbach negative are grainy and rough, especially in the parts that represent the shadows of the photograph. But this defect in the "grating" process does not prevent the production of good printing plates, and the Meisenbach process has been very successful in Europe, 
where it has been operated under the personal supervision of Meisenbach himself. Its most marked defect is a tendency to produce muddy shadows, and considerable loss of color in the middle shades of the picture. The plates also require considerable fixing up, which is done very skilfully by burnishing, rouletting and re-etching. Considerable hand-work is also usually done upon the glass positive, to emphasize outlines, faint details, etc. The process itself is cheap cnough to admit of the employment of skilled hand labor to help it out in this way, but many publishers decidedly prefer purcly photo-mechanical work, which cannot distort outlines and change expressions.

There are new and better " grating " processes now in operation, perfectly distinct from that of Meisenbach, and combining some of the merits of each of the older methods, but they have not been published. Already these processes, none of which were in operation seven years ago, replace millions of dollars worth of wood engraving annually. In a single establishment in our own city, 3,000 of these plates were made during the past year, and hundreds of them have appeared in our illustrated magazines. I have prepared one frame of pictures to illustrate how perfectly these plates may be made to replace wood engravings. Eight pages have been taken from Harper's Magazinc, four containing wood engravings and four Ives process plates of similar subjects. Three wood engravings are from artists' brush drawings, and three process plates are from similar drawings by the same artists. One wood engraving is from a photograph from nature, and one process plate is from a sinilar photograph made by the same photographer. The general effect is the same, and it is admitted by critics that the process plates, which only cost about one-third as much as the wood engravings, arequite equal to them in quality. The process plates here shown were finished without retouching of any kind-they are what we call "pure process work." But it must be confessed that many plates made by the same process are not as satisfactory as these, because the copy supplied, brush, drawing or photograph, is not so suitable for photo-copying.

There is one other kind of photography, which has never been successfully realized, but which I shall say something about, because I have to announce what I believe to be a definite and important step in advance. I refer to photography in colors. 


\section{ELELIOCHROMY.}

There are two distinct methods of making color photographs, in which the distribution of color is regulated by photographic action of the light itself. In one of these methods, the colors are produced directly by the action of light upon a peculiar silver compound; in the other, no colors are produced, but the action of light upon color-sensitive plates is made to regulate the distribution and combination of colors which constitute the final picture. Both of these methods have been made to produce pictures in which the blues, greens, ycllows and reds of an object were represented in a general way by biues, greens, yellows and reds.

The first recorded observations on the photographing of colors by the first method, were made by Dr. Seebeck, of Jena, in $1810-$ twenty-nine years before the discovery of the Daguerrcotype process. A brief translation that has been published, reads as follows: "When I directed the spectrum of a faultless prism (so placed that the incident angle of the front became equal to the refracting angle of the back) on white chloride of silver spread upon paper and still wet, through an opening of about five to six lines in the shutter, and to the distance where the yellow just meets with blue, and kept it by a proper arrangement in this position from fifteen to twenty minutes, I found that chloride of silver changed as follows: It had become red-brown in the violet (occasionally more violet, at other times more blue), and this coloration reached also beyond the line of the violet designated before, but was not deeper than in the violet. In the blue of the spectrum the chloride of silver became true blue, and this color decreasing and gradually gretting lighter, extencled into the green. In the yellow I found the chloride of silver mostly unchanged; sometimes it appeared to me more yellow than before; however, in the red, and often a little beyond the red, it had taken the red of a rose." Sir John Herschel, in August, 1839, alluding to results obtained in substantially the same manner, said: "The red is tolerably vivid, but is rather of a brick color than a pure prismatic red. The green is of a sombre metallic hue, the blue still more so, and rapidly passing into blackness. The yellow is deficient." Edmond Becquerel, in 1848 , Neipce de St. Victor, in $185 \mathrm{I}$, Poitevin, in 1865 , and St. Florent, in 1873, made some advances upon this method, but the results obtained have never had any practical 
value. The process is so insensitive as to require hours of exposure in order to secure camera pictures of objects illuminated by direct sunlight, and the colors obtained, which are neither correct nor sufficiently brilliant, cannot be fixed. The researches of $M$. Carey Lea, of this city, appear to have thrown some further light upon this subject, but have not yet helped to the production of any better results. Most people who are interested in this subject expect the problem to be solved by a method of this character; a few, including myself, do not.

Permanent and far more brilliant pictures have been made by the second method I have mentioned, which was originally suggested by Henry Collen, of England, in 1865 , as follows :

"It occurred to me this morning that if substances were discovered sensitive only to the primary colors - that is, one substance to each color, it would be possible to obtain photographs with the tints as in nature by some such means as the following:

"Obtain a negative sensitive to the blue rays only; obtain a second negative sensitive to the red rays only; and a third sensitive to the yellow rays only.

"There will thus have been three plates obtained for printing in colors, and each plate having extracted all its own peculiar color from every part of the subject in which it has been combined with the other two colors, and being in a certain degree analogous to the tones used in chromo-lithography. Now it is evident that if a surface be prepared for a positive picture, sensitive to yellow rays only, and that the two negatives, sensitive only to blue and red, be superimposed either on the other, and be laid on this surface, the action of light will be to give all the yellow existing in the subject, and if this process be repeated on other surfaces sensitive only to red or blue, respectively, there will have been produced three pictures of a colored object, each of which contains a primitive color reffected from that object.

"Now, supposing the first great object achieved, viz., the discovery of substances or preparations, each having sensitiveness to each of the primary colors only, it will not be difficult to imagine that the negatives being received on the surface of a material quite transparent and extremely thin, and that being so obtained are used as above-i. $e$, each pair of superimposed negatives to obtain the color of the third - that three positives will be obtained, each 
representing a considerable portion of the form of the object, but only one primary of the decomposed color of it. Now, if these three positives be received on the same kind of material as that used for the negatives, and be then laid the one on the other, with true coincidence as to the form, and all iaid upon a white surface, it will not be difficult to imagine that the effect would be, not only the representation of the form of the object, but that of its color also, in all its compounds.

"Although the idea I have endeavored to express in words may be utterly worthless, I am unwilling to let it slip away without notice, as it may, on the other hand, contain a germ which may grow and bear fruit in due season." *

Ducos du Hauron, of Paris, appears to have been the first to attempt to realize a practical process of this character. The theory of his method is substantially the same as that of Collen, but the details of his process were somewhat simplified. Instead of trying to produce plates sensitive only to simple colors, he proposed to employ plates sensitive to all colors, and to filter the light through suitable colored glasses, which amounts to the same thing. He also proposed to allow two colors to act upon each sensitive plate, instead of combining two negatives for the purpose of producing each pigment print; the result would be the same.

Now this method of Collen and Hauron is evidently based on Sir David Brewster's theory of the nature of light, which is, that there are only three primary colors, and that all the other colors and shades of color in the spectrum result from the combination of these in different proportions. It has been clearly established that this theory is false, and that the color of no part of the spectrum can be truly reproduced by the optical combination of other parts. On the other hand, it is true that the eye is readily deceived by

* Collen was Queen Victoria's teacher of drawing, and was not at plotographer. His statcment of his theory, if taken literally, is not perfectly consistent; he says "negative" when he means " sensitive plate," "sensitive to yellow" when he means "producing a yellow picture," etc., but ho makes his meaning sufficiently clear when he adds, in one place, that he would employ "each pair of superimposed negatives to obtain the color of the third." If he had taken more time to formulate his theory, he would doubt. less, have stated it accurately. 
such combinations, which may therefore be regarded as more or less successful counterfeits of the true colors. The painter who copies after nature does not attempt to secure green pigments that will analyze like chlorophyl in the spectroscope, but is satisfied to produce a color that appears the same to the eye, and readily does so. It is really possible to successfully counterfeit all the colors of the spectrum by means of three transparent solutions of seemingly pure color, separate and mixed in different proportions. A photographic method that would accomplish this selection and combination of type colors automatically, and in such a scientific manner as would invariably secure the representation of cach distinct spectrum color by a definite and suitable color mixture, would, I believe, be the nearest approach to accurate photography in colors that we are likely ever to realize. Now it might appear, at first glance, that Hauron's process, although developed on a basis of false theory, would secure such a result. It will not. Although Hauron's description of his color-screens is not specific, from a scientific point of view, there is sufficient evidence that his process was, at best, merely calculated to divide the spectrum into three parts, each of which would be represented by one negative only, and by a single type color in the final result; a heliochrome of the spectrum itself, made in this way, would therefore be nothing more than three strips of even color, abruptly joined together at the edges, but combined in no other way. In practice, Hauron was very far from realizing even so much as this; a heliochrome of the spectrum itself, made by his latest and most approved process (1879), would be black where it should be red, reddish-black or brown where it should be orange, and red where it should be yellow. Albert, Bierstadt and others, who experimented with this method, obtained better results than Hauron, but all failed to realize a successful process.

This method, although it had to be abandoned as utterly unreliable, was found to reproduce many pigment colors very well indeed. This result was due to the fact that all bright pigments reflect the light of two or more parts of the spectrum, and in some cases, by mere coincidence, in such proportion as will secure for them approximately correct representation by a process that is incapable of producing a fair counterfeit of the spectrum. Inasmuch, however, as we do sometimes have to deal with nearly purc 
colors, and the composition of the mixed colors is also infinitely varied, it is evident that a heliochromic process, in order to be successful, must be capable of counterfeiting the spectrum itself,

Such a process I have devised, and will now undertake to describe for the first time. As I have said, I rejcct the theory of three primary colors, recognizing the fact that the color of each part of the spectrum is perfectly distinct from that of every other part; I do not attempt the impossible feat of actually reproducing each ray of simple color, but I undertake to make each ray of simple color select, in a definite manner, and quite automatically, such a combination of type colors as will successfully counterfeit it to the eye.

Before proceeding to describe the process, I will illustrate the difference that may exist between true spectrum colors and very perfect counterfeits of the same. I will do this by analyzing various bright colors with a projection spectroscope. It will be seen that aniline yellow, which counterfeits the yellow of the spectrum, is really a perfect mixture of all colors except blue and violet. Aniline green, which counterfeits the dark green of the spectrum, is a mixture of green, blue and deep red. Aniline violet, which counterfeits the violet of the spectrum, is as much blue and red as violet. I could show you a great many other equally striking examples, but these are sufficient to illustrate my remarks.

In order that I may make the theory of my process clear in a few words, I will commence by giving a list of the requisites for carrying it out, as follows:

(I) Transparent colored solutions, which counterfeit three simple spectrum colors, and can be made to counterfeit all others by mixing in different proportions. I call these my "reproduction colors."

(2) Photographic plates sufficiently sensitive to all parts of the visible spectrum.

(3) Means for filtering out, in a strictly accurate manner, such colored rays, and in such quantity or proportion, as may be required.*

* Compound color-screens produced in the manner indicated in a colnmunication published in this Journal, 122, 123 . 
(4) A camera that will produce three negatives simultaneously, of exactly the same size, and from the same (or very nearly the same) point of view.

(5) Means for producing, from the three negatives, pictures colored by the three solutions described above, and means for combining the three colored pictures.

All of these things I have; but to go into the details of their production would occupy too much time. My process, then, to be brief, consists of making three negatives, on color-sensitive plates, which are exposed simultaneously in a triple camera, behind light filters that are carefully adjusted to transmit to each plate just the kinds and amount of light that will cause the resulting negative to make a colored picture, which, when combined with the other two colored pictures produced in the same manner, will counterfeit the colors of the spectrum, or the colors and light and shade of any object. In order to accomplish this, each spectrum color that is not counterfeited by any one reproduction color, must, of course, be represented by two negatives, in such a manner as will secure a definite and suitable combination of two reproduction colors in the final result.

I believe I have made my meaning clear, but will try to illustrate by reference to a diagram of the spectrum.

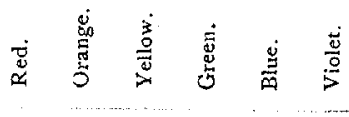

\begin{tabular}{|c|c|c|c|}
\hline Spectrum colors, & A & B & $\mathrm{c}$ \\
\hline $\begin{array}{l}\text { Keproduction colors, } \\
\text { Negratives, }\end{array}$ & 3 & 2 & $\begin{array}{l}3 \\
3\end{array}$ \\
\hline
\end{tabular}

If $m$, reproduction colors $I, 2$ and 3 counterfeit the spectrum at $A, B$ and $C$, the spectrum at $A$ must be represented exclusively in negative $N o . I$, the spectrum at $B$ exclusively in negative $N o .2$, and the spectrum at $C$ exclusively in negative No. 3. Orange, occupying a position in the spectrum midway between $A$ and $B$, is counterfeited by an equal mixture of reproduction colors $I$ and 2 , and must therefore be equally represented in negatives $I$ and 2 ; in the same way, green in negatives 2 and 3 , and violet in negatives 3 and $I$ (you will observe that I propose to counterfeit violet by a mixture of blue and red). Orange-red must be represented Whole No. Vol. CXXV.-(Third Series, Vol. xcv.) 
in negatives $I$ and 2 , but chiefly in 1 ; orange-yellow in the same negatives, but chiefly in 2, and so on.

All this can be accomplished in a most satisfactory manner, by the employment of special compound color-screens, which are adjusted by experiment upon the spectrum itself, in the manner originally suggested by me in a communication to the FRANkLIN Instirute, in June, 1886 . It is true the amount of labor involved in the adjustment of these color-screens is something enormous, but when it is done, it is done for all time.

The pictures may either be made in pigmented gelatine like Hauron's, or ordinary lantern slides from the negatives may be projected by means of a triple optical lantern and light of three colors. In the former method, the process is complicated by the fact that the pigment prints must in each case be of a color coniplementary to that of the mixture of color which produced tlie negative; in the latter method, each negative is represented by the reproduction color counterfeiting that which has been most active in its production. The latter method is the one I shall employ in demonstrating the process to you.

Although I have gone far enough into this subject to convince you that such a process must be a difficult one to reduce to successful practical operation, I have not yet spoken of one of the most serious difficulties that has been encountered; I refer to the difficulty of producing sets of negatives which bear a certain essentia! relation to each other in the matter of exposure, development and intensity. No matter how perfectly we may reproduce bright colors spread out on flat surfaces, the process will fail when we come to deal with the light and shade of objects in relief, if any one of the negatives or positive prints is relatively over or underexposed, or over or under-developed, or too intense, or too thin. In such a case, a yellow which reproduced perfectly in the light shades of the picture, might appear orange, green or slate-colored in the shadows, or vice versa, and other colors would be equally imperfect. I find it necessary to prepare the three sensitive plates at the same time, with the same emulsion, and to develop them in the same developing solution, for the same length of time. Even with this precaution, the results are not perfect unless the sensitive plates are of a certain character, giving harmonious graduation from extreme high light to deepest shadow. 
Evidently a process may be perfectly correct in principle and yet depend for its success upon conditions so difficult to attain that it will fail in practice. I kelieve that this process, although essentially difficult, may nevertheless be so perfected that it will not only counterfeit all the colors of Nature, but be practical and reliable in the hands of specialists who are properly instructed and equipped to operate it. If so, it will have very great value, even if applied only in the manner I shall show you to-night, and for a single purpose, which will suggest itself.

"The proof of the pudding is the eating." I have not yet proved the value of this process. Although I commenced work on it nearly eleven years ago, I have made only half a dozen full regular sets of negatives, and most of those were destroyed by fire at 7 I 5 Arch Street two years ago. My recent experiments have been devoted to perfecting certain details only. The single example that I shall show you to-night is my first and only attempt at a landscape, made more than six years ago, with comparatively crude apparatus and imperfect adjustment of color-screens. It is, how. ever, a very remarkable picture, with colors scarcely less brilliant than they would appear on the ground glass of a camera, and substantially correct to the eye in every shacie and detail.

I hope some time to be able to show hundreds of such pictures, all better than this one.

This illustration suggests one of the easiest and most profitable of the many possible applications of the method, viz., the illustration of popular lectures on travel, like those of Stoddard or Wilson. I feel sure the time is not far distant when that much, at least, will be successfully accomplished. 